\title{
Acne inversa: difficulties in diagnostics and therapy
}

\author{
Beata Bergler-Czop, Karolina Hadasik, Ligia Brzezińska-Wcisło \\ Department of Dermatology, Silesian Medical University, Katowice, Poland \\ Head of the Department: Prof. Ligia Brzezińska-Wcisło MD, PhD
}

Postep Derm Alergol 2015; XXXII (4): 296-301

DOI: $10.5114 / p d i a .2014 .44012$

\begin{abstract}
Acne inversa (hidradenitis suppurativa) is a potentially severe and chronic inflammatory disease with a significant negative influence on the quality of life. Usually, lesions are located in the areas of skin folds and it is characterized by the presence of painful nodules and fistulas with a tendency to tissue fibrosis. Currently, it is suggested that follicular occlusion by infundibular hyperkeratosis plays a crucial role in pathogenesis and an occupation of apocrine sweat glands is a secondary phenomenon. Most often, it refers to men after puberty. This article tries to present the latest theory concerning the etiology of inverted acne and methods of its treatment. It also describes the most common errors in diagnostic and therapeutic procedures, which are mainly connected with repeated and long antibiotic therapy and not radical surgical treatment.
\end{abstract}

Key words: acne inversa, etiology, treatment.

\section{Introduction}

Acne inversa (hidradenitis suppurativa) is a potentially severe and chronic inflammatory disease with a significant negative influence on the quality of life. Usually, lesions are located in the areas of skin folds and it is characterized by the presence of painful nodules and fistulas with a tendency to tissue fibrosis [1, 2]. Stigmatization, depression and anxiety are the highest among patients with clinical changes in the anal and genital area (Figures 1 A-C, 2 A, B).

To this day, there have been discussions whether the disorder belongs to a group of acne or it is a completely different disease entity. Currently, it is suggested that follicular occlusion by infundibular hyperkeratosis plays a crucial role in pathogenesis and an occupation of apocrine sweat glands is a secondary phenomenon. Most often, it refers to men after puberty. Its incidence is $1: 600$ in Caucasians, but higher in patients of African origin. Average prevalence varies in different regions of the world, from < $1 \%$ to $4 \%[1,3,4]$.

Affected areas include: gluteal area, groins, axillae, anogenital area and scalp (Table 1). Although isotretinoin cures acne, in case of this disease it works only sporadically.

\section{Etiology}

Etiology of the inverted acne, as mentioned earlier, is not entirely clear (Table 2). Familial occurrence of this disease was confirmed, but both genetics and the inheritance pattern in most patients require further researches. In Chinese, Japanese and European families, the mutation of $\gamma$-secretase - NCSTN, PSENEN and PSEN1 - genes was described. $\gamma$-Secretase is one of many subunits of the protease complex, which cleaves transmembrane proteins. It is also essential for an appropriate processing of the Notch protein, which is suggested as a key for the etiology of acne inversa. The best known substrate of $\gamma$-secretase is the amyloid precursor protein, which is an integral membrane protein. Thus, amyloid deposits were also described in patients with inverted acne [3, 5-7].

The bacteriological test of patients with acne inversa points to the lack of bacterial flora or mixed flora containing Gram-positive and Gram-negative bacteria. In deep biopsies of lesions, coagulase-negative staphylococcican sometimes be found. Researchers suggest that it indicates disorders of cellular innate immunity in relation to the physiological flora, probably also in saccharomyces. In patients with inverted acne, skin lesions hardly ever cause fever, sepsis or lymphadenopathy. Laboratory tests conclude accelerated OB, increased leukocytosis and other markers of the chronic inflammatory process $[1,8,9]$.

Histopathological analysis demonstrates infundibular hyperkeratosis, hyperplasia of the follicular epithelium, perifolliculitis and creation of pimples and blackheads, which can imitate acne vulgaris in the early stage of the disease. Apocrine glands are unchanged. In the later

Address for correspondence: Beata Bergler-Czop MD, PhD, Department of Dermatology, Silesian Medical University, 20/24 Francuska St, 40-027 Katowice, Poland, phone: +48 501352 033, e-mail: bettina2@tlen.pl

Received: 8.01.2014, accepted: 7.03.2014. 

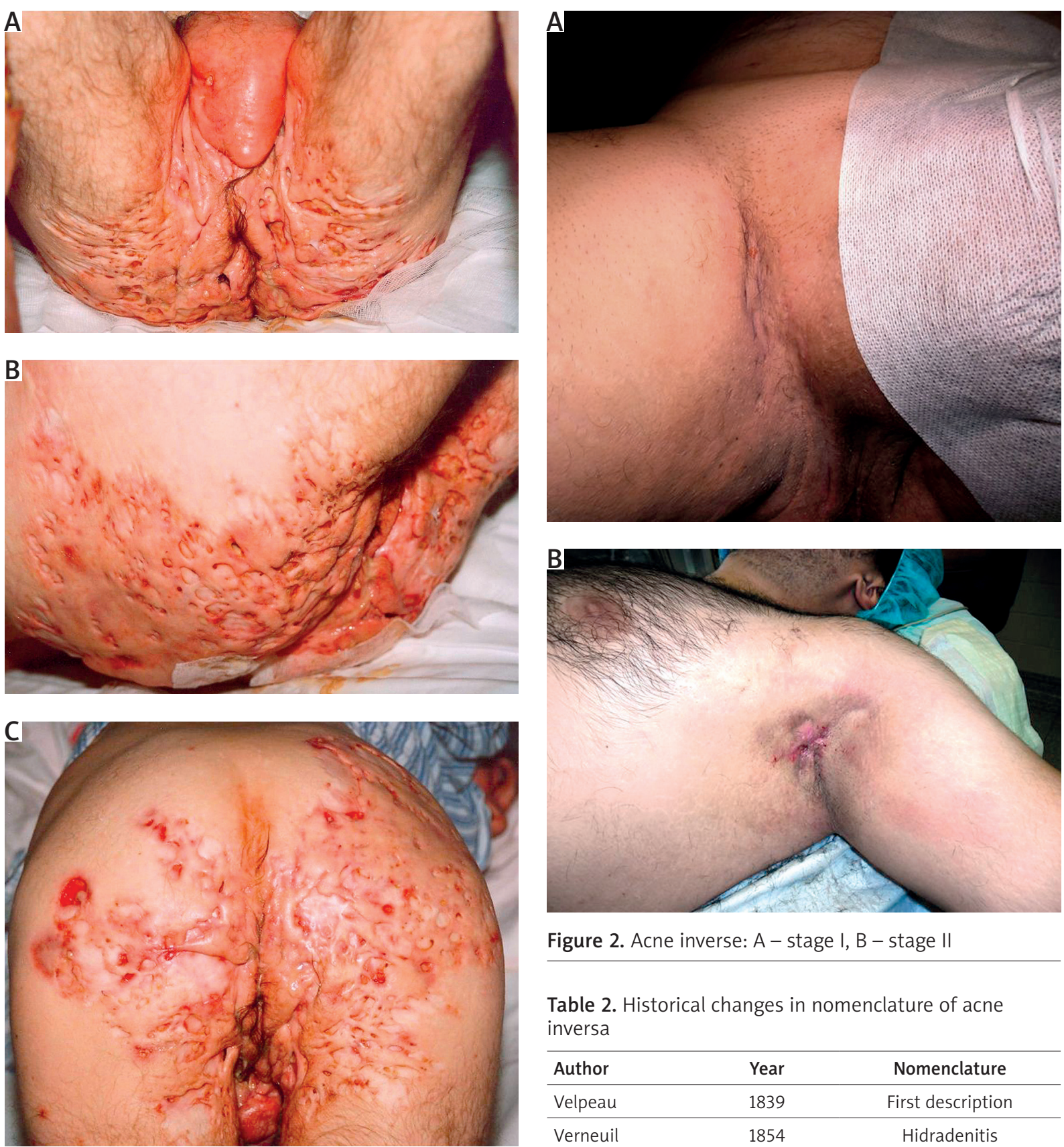

Figure $1 \mathrm{~A}-\mathrm{C}$. Severe acne inversa - stage III

Table 1. Location of skin changes in acne inversa

\begin{tabular}{lccc}
\hline Location & $\begin{array}{c}\text { All } \\
(n=106)[\%]\end{array}$ & $\begin{array}{c}\text { Female } \\
(n=45)[\%]\end{array}$ & $\begin{array}{c}\text { Male } \\
(n=61)[\%]\end{array}$ \\
\hline Armpit & 61.3 & 75.6 & 50.8 \\
\hline Groin & 70.8 & 55.6 & 82.0 \\
\hline Anogenital & 15.1 & 20.0 & 11.5 \\
\hline Others & 34 & 42.2 & 27.9
\end{tabular}

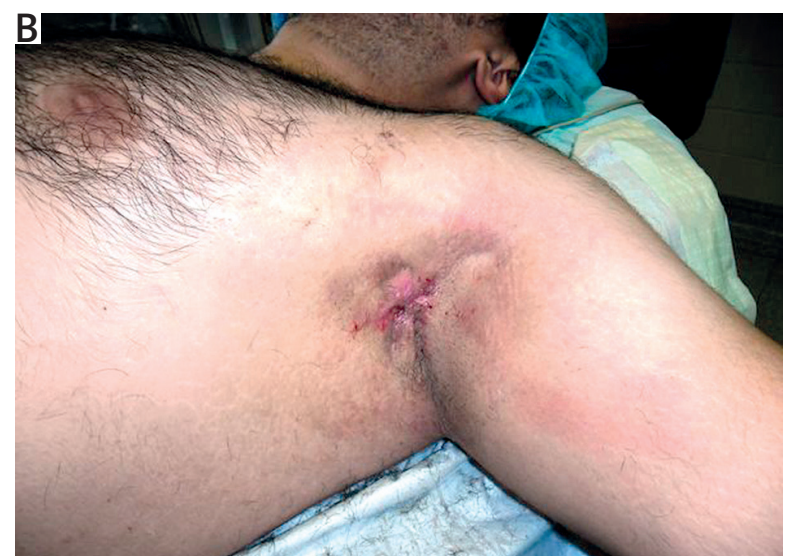

Figure 2. Acne inverse: A - stage I, B - stage II

Table 2. Historical changes in nomenclature of acne inversa

\begin{tabular}{llc}
\hline Author & Year & Nomenclature \\
\hline Velpeau & 1839 & First description \\
\hline Verneuil & 1854 & Hidradenitis \\
\hline Schifferdecker & 1922 & Apocrine glands \\
\hline Lane & 1934 & Acne group \\
\hline Kligmann & 1956 & Follicle occlusion triad \\
\hline Gehlen & 1976 & Severe acne \\
\hline Plewig & 1988 & Inverted acne \\
\hline
\end{tabular}

stage, images of ruptured hair follicle and severe inflammatory infiltration are visible. Also at this stage, apocrine glands remain unchanged. In the case of restriction of the inflammatory process to the area of hair follicle, neutrophils are gradually displaced by granulomatous cells (inflammatory reaction - foreign body type). In the case of 
a more severe inflammatory reaction, an abscess, which can reach the subcutaneous tissue, is formed. In the late stage, we can observe fistulas, fibrosis of dermis and subcutaneous tissue and massive inflammation reaction [1].

It is not clear what causes an occlusion of hair follicles in the course of acne inversa. It is believed that it may be the hyperkeratosis, similar to acne vulgaris. Other possibilities are chemokines and cytokines synthesized by keratinocytes, which are inflammatory and they cause the migration and proliferation of keratinocytes. Soluble interleukin-2 receptor also seems to play a role in the pathophysiology. Seventy-seven percent of skin biopsies in patients with inverted acne demonstrated a severe hyperplasia of hair follicles epithelium. Histological researches of patients with inverted acne did not demonstrate the presence or reducing the size of sebaceous glands. Inflammatory infiltrate contains tryptasepositive mast cells, T CD-3-positive lymphocytes, CD 138-positive plasma cells. As a result of damage, we can observe an additional influx of leukocytes, neutrophils and macrophages. Later in the infiltration, we can see C20+ and CD79a + cells. Lesions and surrounding skin also contains pro-inflammatory cytokines, such as: IL-1 $1 \beta$, IL-10, TNF- $\alpha$ and macrophages with an expression of TLR2 receptors, AMP antimicrobial peptides, IL-23 and IL-12, IL-10, IL-17 (what in some way looks like infiltration in Crohn's disease and psoriasis). In 43\% of cases, it was also observed similar to psoriasis hyperplasia of epidermis and intra-follicular and intra-epidermal inflammatory infiltration: CD 3, CD 4, CD 68, CD 79 and CD8. Described factors are considered to be early markers of acne inversa type changes. In comparison with a healthy skin, a significantly higher expression of Toll-like type 2 (TLR2) receptors was found. Infiltration was dominated by $C D$ 68+ macrophages, CD 209+ dendritic cells DC and T CD3 lymphocytes. TLR2 expression was primarily observed in CD 68+ macrophages and CD 209+ dendritic cells DC. Interestingly, similar features are present in the infiltration in typical changes in the course of acne vulgaris [10-12].

Population-based studies demonstrated that obesity and smoking are risk factors for the formation of acne inversa type changes. Ninety-six percent of patients with hidradenitis suppurativa smoked more than 20 cigarettes, and $50 \%$ of them were overweight. It is believed that nicotine acts by intensity of hyperkeratosis in hair follicles, inhibition of neutrophil apoptosis, stimulation

Table 3. Hurley's classification

\begin{tabular}{ll}
\hline Stage & \multicolumn{1}{c}{ Description of skin changes } \\
\hline I & Abscesses single or multiple, no fistulas and scars \\
\hline II & $\begin{array}{l}\text { Chronic abscesses with fistulas and scars, single } \\
\text { or multiple }\end{array}$ \\
\hline III & $\begin{array}{l}\text { Disseminated changes in several location with } \\
\text { abscesses, bridge-type scars and fistulas }\end{array}$ \\
\hline
\end{tabular}

of chemotaxis, increase of hydro-oxidation of estrogens, vasoconstriction, decrease in saturation via oxygen and decrease in the production of prostacyclins [13].

Moreover, the role of hormonal factors in the acne inversa etiology was described. The disease almost always starts after the puberty, and it completely or partially disappears after the menopause $[1,14]$. The impact of androgens on the course of the hidradenitis suppurativa is also contemplated, but most patients have correct hormonal tests.

Increased prevalence of obesity and diabetes is shown in patients with hidradenitis suppurativa. Probably, the obesity provokes a friction of skin in folds what contributes to the severity of keratosispilaris. There are also reports about the provocation acne inversa with lithium, corticosteroids or some vitamins [1, 15].

\section{Clinical stages, symptoms}

Severity of acne inversa is classified into three stages according to Hurley scale, which relies on the subjective extent of the disease (Table 3).

Hidradenitis suppurativa can be associated with inflammatory bowel diseases, spondyloarthropaties, folliculitis, congenital disorders of keratinization and squamous cell carcinoma. Co-morbidity with diabetes, hypercholesterolemia, acne vulgaris, poor hygiene, use of deodorants, depilation, maceration and occlusion was not demonstrated [3, 13].

The most common complications of inverted acne are scarring and infections. Due to the chronic inflammatory process, systemic complications may also appear, such as anemia, hypoproteinemia, nephrotic syndrome, arthropathies, secondary lymphoedema (scrotum, vulva), rectum, vagina, urethra and bladder fistulas [13].

Reactive arthritis can develop as a possible complication of acne inversa. Inflammation of synovial membrane - synovitis, acne, hyperostosis and osteoarthritis were described in patients with Al as so-called SAPHO (synovitis, acne, pustulosis, hyperostosis) syndrome. There were also cases of coexistence with pyoderma gangrenosum and secondary amyloidosis with systemic involvement of the heart and kidneys. Another complication is an interstitial keratitis, which can lead to the perforation [3].

A life-threatening complication is the squamous cell carcinoma. It is relatively rare but these tumors are aggressive with a tendency to early metastases [13].

Differential diagnosis includes: abscessus perianalis, furuncles, fistulas, actinomycosis, tuberculosis, deep fungal infection (mycosis), atypical mycobacteriosis NTM/ MOTT, inguinal granuloma (donovanosis) and also pyoderma gangrenosum [3].

Diagnostic mistakes are very common. They lead to therapeutic errors, because treatment of inverted acne significantly differs from the therapy in diseases, which are mentioned in differentiation. It leads to a number of 
treatment failures. An especially popular mistake is treating of lesions as furuncles or acne vulgaris.

\section{Treatment}

Standards of acne inversa therapy are presented below (Table 4).

Pharmacological treatment of acne inversa usually brings only short-term effects. However, due to possible contraindications for the surgical treatment, as well as concerns of patients connected with this type of therapy, a conservative therapy is often initially recommended $[15,16]$.

Quite often, general (tetracycline, minocycline, ciprofloxacin, clindamycin, cephalosporins) or local antibiotics (erythromycin, clindamycin) are recommended as treatment of choice. However, due to only short-term effects of this therapy, they should be used only in exacerbations of the disease or as the perioperative treatment. Recently recommended therapy is a combination of clindamycin with rifampicin $[13,15,16]$.

Vaccines from one's own bacterial material, bacteriophages and medicines stimulating an immune response have a limited effectiveness in acne inversa. Isotretinoin does not work either. It is recommended only in the preoperative period (approximately 3 months in a dose of $0.6-1 \mathrm{mg} / \mathrm{kg}$ ). In the literature, there are also reports about the effectiveness of dapsone in a dose of 25$100 \mathrm{mg} /$ day. However, long-term effects of this treatment are rarely mentioned. Anti-androgenic therapy is considered to be effective only in the first stage of disease and location in the genital area. Therapy trials also included $5 \alpha$-reductase-finasteride inhibitor at a dose of $5 \mathrm{mg} / \mathrm{day}$ $[14,15]$.

Recent reports also describe different treatment regimens by biologicals: infliximab, etanercept, adalimumab, efalizumab and others. This therapy, despite a high recommendation (2012), is still not approved by the FDA, and treatment regimens are different. Infliximab was used in a dose of $5-10 \mathrm{mg} /$ day every 4 weeks during the period from 5 months to 4 years. A good response was obtained in $80 \%$ of patients in II and III stage of inverted acne after just only 3-7 applications of the medicine. Etanercept in a dose of $2 \times 25 \mathrm{mg} /$ week was recommended by $17-40$ weeks. Efalizumab in several cases was added in a dose of $1 \mathrm{mg} / \mathrm{kg} / \mathrm{month}$ at weekly intervals for a period of 6 months. Adalimumab was also used in a few regimens. In 3-month therapy, 15 patients in II and III stage obtained a significant improvement, expressed by a decrease in VAS and DLQI. In all patients, medicines were well tolerated [13, 16-20].

In inverted acne, it was also tried to use intravenous immunoglobulin given once a month at a dose of 8-12 g for 1-15 months. In other cases, usually a short-term improvement was obtained by using X-ray radiotherapy, photodynamic therapy, local corticosteroids injections, compresses from $10 \%$ ichthyol ointment or moist application of chlorhexidine. However, the aforementioned methods were characterized by a limited effectiveness and they were recommended only in the first stage of disease. An alternatively used method is cryotherapy, usually spraying of liquid nitrogen $[15,17]$.

The treatment of choice in acne inversa is a surgical intervention. Unfortunately, quite common concerns of patients concerning this method of therapy causes that it is deferred what worsens results of treatment. Successful surgical interventions are connected with a complete excision of diseased tissues with a margin of healthy skin, with the closure of defects caused by self-healing, primary sewing, local flap plastic surgery/plasty and transplant/graft plasty. Sometimes, several such interventions are necessary $[15,16]$.

The extent of skin lesions is best determined by the preoperative palpation test, where indurations and fistulas can be felt. Excision should concern lesions, full thickness of subcutaneous tissue/hypodermis and variously defined margins of healthy skin (some specialists recommend $1 \mathrm{~cm}$ ). Fascia with muscles is less cut out.

A scalpel, electric scalpel or ablative laser $\left(\mathrm{CO}_{2}\right)$ is used for resection. The simplest option of healing is an intrinsic healing. Wound surface is covered with sterile bandages or bandages accelerating granulation tissue. The healing time in this method is $6-12$ weeks. Transplants plastyshortens healing time and usually allows for better aesthetic results. Transplants can be used directly after the surgery or after finishing of bottom's granulation tissue. Smaller defects can be stapled. In the area of armpits, local shifted flap-plasty for example so-called Limberg rhomboid flaps, is recommended. Methods limited to cut-out abscesses and stitch of fistulas are ineffective and not recommended [15, 19-23].

The most common early postoperative complications include: infection, bleeding, impaired wound healing, necrosis of the transplant, necrosis of the flap, injury of brachial plexus, injury of nerves, thrombotic complications of brachial vein. Late complications include: retention of serous discharge, bridge contractures, hypertrophic scars, keloids, recurrence of the disease. Operating contractures are most common within the shoulder joint. Average frequency of relapses is estimated at $2.5 \%$. It mainly concerns the bottom area of the breast $-50 \%$, groins and perineum $-37 \%$ [15]. It is reported that a surgical technique also influences the therapeutic failure

Table 4. Consensus of treatment JDDG 2012

\begin{tabular}{lc}
\hline Treatment & Recommendation level \\
\hline Surgery & 1 \\
\hline Clindamycin-rifampicin orally & 2 \\
\hline Infliximab i.v. & 2 \\
\hline Laser Nd-Yag & 2 \\
\hline
\end{tabular}


apart from the location. Some authors [13] report that in the flap techniques in the area of armpits, the percentage of recurrence is about 40 . In groins - when stapling wound $-12.5 \%$, with flap technique $-33 \%$, and with using transplants, the recurrences were not observed. In the anogenital area, in the flap technique no recurrences were observed and similarly when using transplants to cover the wound on the trunk and in the area of buttocks.

Recommendations of therapies for particular disease stages are as follows [13, 24-26]:

a) I stage according to Hurley: radical surgical resection of tissues occupied by a disease process (excision of single changes is not recommended), healing by a primary stapling of wounds, periodical drainage;

b) II and III stage according to Hurley: radical surgical resection of tissues occupied by a disease process up to muscle fascia (sometimes deeper), thorough removal of fistulas, primary or secondary stapling of the wound, possibly additionally postoperative pharmacotherapy.

Additional recommendations are: nicotine abstinence, local use of disinfectants, periodic antibiotic therapy (controversial), oral isotretinoin $0.6-1.0 \mathrm{mg} / \mathrm{kg} /$ day 3 months before the surgery (treatment should be completed $2-3$ days before the planned surgery) $[13,15$, 27-29].

\section{Conclusions}

This article tries to present the latest theory concerning the etiology of inverted acne and methods of its treatment. It also describes the most common errors in diagnostic and therapeutic procedures, which are mainly connected with repeated and long antibiotic therapy and not radical surgical treatment.

\section{Conflict of interest}

The authors declare no conflict of interest.

\section{References}

1. Scheinfeld N. Hidradenitis suppurativa: a practical review of possible medical treatments based on over 350 hidradenitis patients. Dermatol Online J 2013; 19: 18169.

2. Witmanowski H, Szychta P, Stępniewski S, et al. Acne inversa goes an extra mile than hidradenitis suppurativa. Postep Derm Alergol 2013; 30: 255-60.

3. van der Zee HH, Prens EP. Failure of anti-interleukin-1 therapy in severe hidradenitis suppurativa: a case report. Dermatology 2013; 226: 97-100.

4. Gisondi P, Girolomoni G. Impact of TNF-alpha antagonists on the quality of life in selected skin diseases. G Ital Dermatol Venereol 2013; 148: 243-8.

5. Blanco R, González-López MA, González-Vela MC, et al. Disparate results in studies of adalimumab in the treatment of hidradenitis suppurativa: comment on the article by Amano et al. Int J Dermatol 2013; 52: 380-1.
6. Kimball AB, Kerdel F, Adams D, et al. Adalimumab for the treatment of moderate to severe hidradenitis suppurativa: a parallel randomized trial. Ann Intern Med 2013; 157: 846-55.

7. Blok JL, van Hattem S, Jonkman MF, Horváth B. Systemic therapy with immunosuppressive agents and retinoids in hidradenitis suppurativa: a systematic review. $\mathrm{Br}$ I Dermatol 2013; 168: 243-52.

8. Sotiriou E, Goussi C, Lallas A, et al. A prospective open-label clinical trial of efficacy of the every week administration of adalimumab in the treatment of hidradenitis suppurativa. J Drugs Dermatol 2012; 11: 15-20.

9. van Rappard DC, Limpens J, Mekkes JR. The off-label treatment of severe hidradenitis suppurativa with TNF-alpha inhibitors: a systematic review. J Dermatolog Treat 2013; 24: 392-404.

10. Jemec GB. Hidradenitis suppurativa and immune dysregulation. Br J Dermatol 2012; 166: 237-8.

11. van der Zee HH, Laman JD, de Ruiter L, et al. Adalimumab (antitumour necrosis factor-alpha) treatment of hidradenitis suppurativa ameliorates skin inflammation: an in situ and ex vivo study. Br J Dermatol 2012; 166: 298-305.

12. dos Santos CH, Netto PO, Kawaguchi KY, et al. Association and management of Crohn's disease plus hidradenitis suppurativa. Inflamm Bowel Dis 2012; 18: 801-2.

13. van Rappard DC, Leenarts MF, Meijerink-van 't Oost L, et al. Comparing treatment outcome of infliximab and adalimumab in patients with severe hidradenitis suppurativa. J Dermatolog Treat 2012; 23: 284-9.

14. Miller I, Lynggaard CD, Lophaven S, et al. A double-blind placebo-controlled randomized trial of adalimumab in the treatment of hidradenitis suppurativa. Br I Dermatol 2011; 165: 391-8.

15. Amano M, Grant A, Kerdel FA. A prospective open-label clinical trial of adalimumab for the treatment of hidradenitis suppurativa. Int I Dermatol 2010; 49: 950-5.

16. Arenbergerova M, Gkalpakiotis S, Arenberger P. Effective long-term control of refractory hidradenitis suppurativa with adalimumab after failure of conventional therapy. Int J Dermatol 2010; 49: 1445-9.

17. Reddick CL, Singh MN, Chalmers RJ. Successful treatment of superficial pyoderma gangrenosum associated with hidradenitis suppurativa with adalimumab. Dermatol Online J 2010; 16: 15.

18. Karampetsou MP, Liossis SN, Sfikakis PP. TNF-alpha antagonists beyond approved indications: stories of success and prospects for the future. QJM 2010; 103: 917-28.

19. Brunasso AM, Massone C. Rotational therapy with TNFalpha blockers for recalcitrant hidradenitis suppurativa. Eur J Dermatol 2010; 20: 644-6.

20. Shuja F, Chan CS, Rosen T. Biologic drugs for the treatment of hidradenitis suppurativa: an evidence-based review. Dermatol Clin 2010; 28: 511-521, 523-524; quiz 522-523.

21. Matusiak $七$, Bieniek A, Szepietowski J. Inverted acne (acne inversa). Part I: pathogenesis, epidemiology and history. Dermatol Klin 2006; 8: 201-4.

22. Zoubolic CC. Biologics in treatment of hidradenitis suppurativa/acne inversa. $22^{\text {nd }}$ Congress of the EADV 2-6 October 2013 Istambul.

23. Matusiak $Ł$, Bieniek A, Szepietowski J. Inverted acne (acne inversa). Part II: surgical and pharmacology treatment. Dermatol Klin 2006; 8: 298-301.

24. Moschella SL. Is there a role for infliximab in the current therapy of hidradenitis suppurativa? A report of three treated cases. Int I Dermatol 2007; 46: 1287-91. 
25. Poulin Y. Successful treatment of hidradenitis suppurativa with infliximab in a patient who failed to respond to etanercept. J Cutan Med Surg 2009; 13: 221-5.

26. Fonder MA, Cummins DL, Ehst BD, et al. Adalimumab therapy for recalcitrant pyoderma gangrenosum. J Burns Wounds 2006; 5: 66-71.

27. Blanco R, Martínez-Taboada VM, Villa I, et al. Long-term successful adalimumab therapy in severe hidradenitis suppurativa. Arch Dermatol 2009; 145: 580-4.

28. Ah-Weng A, Langtry JA, Velangi S, et al. Pyoderma gangrenosum associated with hidradenitis suppurativa. Clin Exp Dermatol 2005; 30: 669-71.

29. Alkhouri N, Hupertz V, Mahajan L. Adalimumab treatment for peristomal pyoderma gangrenosum associated with Crohn's disease. Inflamm Bowel Dis 2009; 15: 803-6. 